\title{
The impact of pharmacist shortage on the inventory management of medicines at primary healthcare centres in East Java, Indonesia
}

\author{
Abdul Rahem, Umi Athiyah, Catur Dian Setiawan, Andi Hermansyah \\ Faculty of Pharmacy, Universitas Airlangga Surabaya Indonesia
}

\author{
Keywords \\ Inventory \\ Management \\ Medicine \\ Pharmacist \\ Correspondence \\ Abdul Rahem \\ Faculty of Pharmacy \\ Universitas Airlangga Indonesia \\ Level 4 \\ Nanizar Zaman Joenoes Building \\ Campus C Universitas Airlangga \\ Jl. Mulyorejo Surabaya \\ Indonesia \\ abdulrahem@ff.unair.ac.id
}

\begin{abstract}
Background: Pharmacists are the only people authorised to manage the medicines inventory. However, in the case of pharmacist shortage, other personnel may take over this function. This is particularly the case in most primary healthcare centers (puskesmas) in Indonesia. Aim: To compare the outcome of medicine inventory management between pharmacists and nonpharmacists in primary healthcare centres (PHCs). Methods: A survey of 146 puskesmas in East Java was conducted involving 73 pharmacists and 73 non-pharmacist staff. This study was conducted from July to January 2020. Each respondent completed a questionnaire focusing on the inventory aspects of medicine management. Results: Purchasing accuracy is higher for pharmacists $(90 \%)$ than for non-pharmacists $(68 \%)$. Pharmacists manage the inventory more efficiently with only $2 \%$ of the drugs expired and wasted while non-pharmacist staff wasted $16 \%$ of the drugs and $18 \%$ of the drugs expired. Conclusion: The role of pharmacists in medicine inventories is vital as they carry out more efficient and accurate medicine management.
\end{abstract}

\section{Introduction}

The position of pharmacists in community health service facilities is very important because these are the places where people obtain safe, effective and highquality drugs. Community pharmacists must ensure that medicines are efficiently regulated and available in sufficient quantities before focusing on providing clinical pharmacy services (van de Pol et al., 2020). Over the years, several studies have shown that pharmacists spend a lot of time and money on pharmaceutical logistical setups (van de Pol et al., 2019). Pharmaceutical logistic supply chains have unique characteristics so that it has different characteristics from other consumer commodity supply chains. The pharmaceutical supply chain faces uncertainty; for example, the demand for each drug is uncertain and can be affected by seasonal changes (Franco \& Alfonso-
Lizarazo, 2020). The supply chain of pharmaceutical products is characterised by high complexity, and the supply and delivery channels to customers are limited and highly regulated (Merkuryeva, Valberga \& Smirnov, 2019). Since accuracy and skills are required in drug management, careful pharmaceutical management is directly linked to a country's ability to address public health problems (Uthayakumar \& Priyan, 2013). In addition, health service facilities in the community are comfortable places for people to get information or advice from pharmacists regarding medication and drug use (Nunes, Anderson \& Martins, 2015).

Management procurement, storage, and distribution in pharmaceutical preparation are very important for health care facilities and pharmaceutical companies (Uthayakumar \& Priyan, 2013). Health service facilities can plan for drug procurement according to the needs 
of the community around the health facility. The suitability of the management of pharmaceutical preparation with the needs and characteristics of health service facilities (Saha \& Ray, 2019) will be achieved properly if managed by a pharmacist. The availability of drugs at the health centre is very important because the primary healthcare centre (puskesmas) is the leading health service facility. It is the closest to the community and is the main destination of the community for medical treatment (Athijah, Rahem \& Setiawan, 2018), especially in the current era of National Health Insurance (JKN), where puskesmas are one of the first level health service providers (PPK I). In each sub-district, there is at least one puskesmas. Drug availability is an important factor to ensure rational drug use by patients. In addition, drugs also form a link between patients and health care facilities so they can encourage public trust in these health service facilities (Athijah, Rahem \& Setiawan, 2018).

The initial planning step in a drug management series at health centres will affect the availability and suitability of the drugs and needs. Usually, stocking a number of drugs that is not close to the real needs is the main factor that causes empty or excess stock at the puskesmas. Therefore, it requires careful planning by all people in charge of the puskesmas pharmacies (Istiqomah \& Satibi, 2012). Unsuitable drug stock at the puskesmas poses the risk of irrational treatment and will also increase cost, as well as potentially resulting in a large number of damaged or expired drugs. If the stock of drugs at the puskesmas is insufficient or below the required amount, patients do not receive the appropriate medicine, which results in irrational treatment. If the drugs are in excess or exceed the need, this will result in the drugs becoming damaged or expired because they were stored in the puskesmas for too much time (Rahem, 2017). In addition, if the management is not efficient, the number of expired drugs and the management cost will increase at the puskesmas.

Puskesmas are the Technical Implementing Units (UPT) of the district/city Health Service, so it is appropriate that drugs and consumable medical materials are obtained from the district/city Health Office or from regency/city pharmaceutical installations. Therefore, the adequacy of drugs at puskesmas are also determined by their availability at the institution. The planning and procurement of drugs in district/city pharmacy installations is based on data compiled from proposed planning for puskesmas and other health service facilities under the auspices of the Health Office. To accommodate for the recording and reporting that supports the evaluation of drugs and medical supplies, it is necessary to use an information system that is based on drug and transaction data for the process of purchasing and receiving drugs, drug distribution, and drug use and availability (Sanjaya et al., 2013). Information technology systems in the planning and procurement of drugs or what is often called e-purchasing and e-catalogue at health service facilities or the health office are very helpful to speed up the process which affects the availability of drugs (Ningsih, Fudholi \& Sumarni, 2015).

The availability of drugs and consumable medical materials at the health centre depends on the competence of the drug administrator (Athijah \& Rahem, 2018). In accordance with regulation, pharmacists are the ones who have the expertise and authority in relation to pharmaceutical work (Rahem, 2017). Moreover, there has currently been an expansion of the scope of pharmaceutical practice, which initially only focused on drug management; now, it is also obliged to carry out pharmaceutical care to ensure the success of therapy in patients. Drug management is not just how drugs are produced and distributed but also includes where patients get their drugs from, how to use them, from whom they get information about drug use and how they store them at home (Athiyah \& Rahem, 2017). Therefore, pharmacists should run the pharmacy practice or be the person in charge of managing drugs at the puskesmas.

East Java Province had 960 puskesmas in 2016 (National Statistic Bureau, 2016). Unfortunately, not all puskesmas have a pharmacist as the person in charge of the pharmacy, and so there are still many other health workers or non-health workers who manage drugs in the East Java puskesmas. These conditions mean that it is very likely that there will be management differences that impact drug availability in the puskesmas managed by pharmacists and those managed by other personnel. Given that the competence and authority are not in accordance with the management of pharmaceutical preparation requirements, this study aims to analyse the differences in the suitability of the pharmacists and non-pharmacists that are planning the drug needs at puskesmas.

\section{Methods}

This study used a quantitative observational design, with a total of 146 respondents who were administering drugs at puskesmas in East Java. These were divided into two groups, namely 73 pharmacists and 73 non-pharmacist drug administrators. The selection of respondents was carried out by purposive sampling. Respondents managing non-pharmacist 
drugs were selected from health centres that could be accessed via public roads and easily reached by car without having to walk. For the pharmacist respondents who were drug administrators, they were selected using the following inclusion criteria: they had to have been registered as members of the Community Pharmacist in Puskesmas Association (HISFARKESMAS) at the regional board of the Indonesian Pharmacist Association (PD IAI) of East Java and been participating in coaching related to responsible pharmacist practices carried out by the PD IAI of East Java. There were 73 pharmacists who fulfilled the criteria. Therefore, in order to have a balance, 73 non-pharmacist drug administrators from puskesmas were also taken. Ethics approval was not required as this was an evaluative study confirming the practice in inventory management. However, signed consent was obtained from all participants prior to conducting the survey.

Furthermore, the variable in this study was the management of drugs at the puskesmas. The management focuses studied were: the guidelines used as a reference in drug planning, planning time, the quantification method used as a consideration in planning, drug availability, the suitability of the drug requirement plan, expired drugs, damaged medicine, excess stock of drugs, and dead drug stocks.

Data collection was carried out from July 2019 to January 2020. The data collection technique was carried out using a validated questionnaire, which was given to the person in charge of drug management in each selected health centre. Respondents' answers to the questionnaire given were then recapitulated and analysed. Apart from descriptive analysis, inferential statistics were also applied to determine differences in drug availability and the suitability of RKO with drug availability between health centres managed by pharmacists and non-pharmacists. The statistical test used was the independent sample t-test.

\section{Results}

There were $83.6 \%$ female pharmacists and $69.9 \%$ female non-pharmacists included in this study (see Table I). The employment status of the majority of respondents in both the pharmacist and nonpharmacist groups was a civil servant. $67.1 \%$ of respondents in the pharmacist group were civil servants, and $69.9 \%$ of respondents in the nonpharmacist group were civil servants, as shown in Table I.
Table I: Characteristics of respondents

\begin{tabular}{lcc}
\hline Characteristics & $\begin{array}{c}\text { Pharmacists } \\
n(\%) ; n: 73\end{array}$ & $\begin{array}{c}\text { Non- } \\
\text { pharmacists } \\
\mathrm{n}(\%) ; \mathrm{n}: 73\end{array}$ \\
\hline Gender & & \\
Female & $61(83.6)$ & $22(69.9)$ \\
Male & $12(16.4)$ & \\
\hline Length of work as a drug administrator in years & \\
$<1$ & $37(50.7)$ & $16(21.9)$ \\
$1-5$ & $10(13.7)$ & $25(34.3)$ \\
$6-10$ & $13(17.8)$ & $16(21.9)$ \\
$>10$ & $13(17.8)$ & $16(21.9)$ \\
\hline Status of Employment & & \\
Public servant (PNS) & $49(67.1)$ & $51(69.9)$ \\
Non-Public servant (non- & $24(32.9)$ & $22(30.1)$ \\
PNS) & & \\
\hline
\end{tabular}

The results of the study, as shown in Table II, demonstrated the similarities of several things that were done by pharmacists and non-pharmacists, namely: the guidelines used as a reference in planning along with the national formulary. Likewise, the planning time for both pharmacists and non-pharmacists was at the beginning of the year. Receiving drugs that are approaching their expiration date from the Health Office is an interesting experience. All respondents, both pharmacists and nonpharmacists, stated that drugs often reached their expiry date, but at the end of the year, there were more expired drugs in the inventories managed by non-pharmacists.

The results of the study shown in Table II demonstrate that the average availability of drugs at puskesmas was better when managed by pharmacists compared to those managed by non-pharmacists. It was found that there was up to $90 \%$ drug availability in puskesmas managed by pharmacists and up to $70 \%$ for those managed by non-pharmacists. Based on the statistical analysis shown in Table III, the value of $p=0.000$ was obtained, meaning that there was a significant difference in the availability of drugs in the puskesmas that were managed by pharmacists and non-pharmacists.

\section{Discussion}

In this study, regarding drug administrators at the puskesmas, the pharmacist group was in accordance with the research conducted by Satibi and the authors (2018) that showed that the majority of pharmacists in the puskesmas were women (Satibi et al., 2018). On the other hand, the non-pharmacist drug administrators were in accordance with research conducted by Athijah and the authors (2018), which presented that the majority of drug administrators were women (60\%) (Athijah, Rahem \& Setiawan, 2018). 
Table II: Research variables

\begin{tabular}{|c|c|c|}
\hline \multirow[t]{2}{*}{ Variables } & \multicolumn{2}{|c|}{ Drug administrator at the puskesmas } \\
\hline & Pharmacist & Non-pharmacist \\
\hline Guidelines used as a reference in planning & National Formulary & National Formulary \\
\hline Time to plan & Beginning of the year & Beginning of the year \\
\hline Experience of receiving drugs that are almost expired from the Health Office & Often & Often \\
\hline Quantification method used as a consideration in planning & $\begin{array}{l}\text { Consumption, } \\
\text { Epidemiologic } \\
\text { ABC analysis, } \\
\text { Non-essential Essential } \\
\text { Vital (VEN) }\end{array}$ & Consumption \\
\hline Average percentage of drug availability compared to those needed at the puskesmas & $90 \%$ & $70 \%$ \\
\hline $\begin{array}{l}\text { Average percentage of the suitability of the planned drug needs (RKO) with those needed } \\
\text { at the puskesmas }\end{array}$ & $90 \%$ & $68 \%$ \\
\hline $\begin{array}{l}\text { Percentage of excess stock of drugs at the puskesmas (number of drug items with } \\
\text { availability of more than } 18 \text { months of use divided by the number of all drug items at } \\
\text { puskesmas } \times 100 \% \text { ) }\end{array}$ & $10-20 \%$ & $10-40 \%$ \\
\hline $\begin{array}{l}\text { Percentage of expired drugs at the puskesmas (number of expired drugs divided by the } \\
\text { remaining stock of the drug item } \times 100 \% \text { ) }\end{array}$ & $1-2 \%$ & $5-18 \%$ \\
\hline $\begin{array}{l}\text { Percentage of damaged drugs at the puskesmas (number of damaged drugs divided by the } \\
\text { remaining stock of drug items } \times 100 \% \text { ) }\end{array}$ & $1-2 \%$ & $2-16 \%$ \\
\hline $\begin{array}{l}\text { Percentage of dead drug stocks in the puskesmas (number of drug items that never come } \\
\text { out in one year divided by the number of all drug items in the puskesmas } \times 100 \% \text { ) }\end{array}$ & $2-7 \%$ & $2-15 \%$ \\
\hline
\end{tabular}

Table III: Statistical analysis

\begin{tabular}{|c|c|c|c|c|}
\hline \multirow[t]{2}{*}{ Variables } & \multirow[t]{2}{*}{ Types of statistical test } & \multicolumn{2}{|c|}{ Drug administrator } & \multirow[t]{2}{*}{$p$-value } \\
\hline & & $\begin{array}{l}\text { Pharmacist } \\
\text { M } \pm \text { SD }\end{array}$ & $\begin{array}{l}\text { Non Pharmacist } \\
\qquad \mathrm{M} \pm \mathrm{SD}\end{array}$ & \\
\hline $\begin{array}{l}\text { Average percentage of drug availability } \\
\text { compared to those needed at the } \\
\text { puskesmas }\end{array}$ & Independent Samples t-test & $90 \pm 2.224$ & $70 \pm 4.072$ & 0.0001 \\
\hline $\begin{array}{l}\text { Average percentage of the suitability of } \\
\text { the planned drug needs (RKO) with those } \\
\text { needed at the puskesmas }\end{array}$ & Independent Samples t-test & $90 \pm 2.291$ & $68 \pm 2.144$ & 0.0001 \\
\hline
\end{tabular}

Respondents' work experience differed between the pharmacist and non-pharmacist groups. For the pharmacist group, the majority $(50.7 \%)$ had less than one year worth of experience. This is understandable because the recruitment of civil servants for pharmacists in a relatively large number of health centres has only been carried out after a circular from the Minister of Health of the Republic of Indonesia in early 2018 regarding the need for pharmacist placement at puskesmas. The experience in drug management in puskesmas for the non-pharmacist respondent groups were seen to be more evenly distributed in all groups, as seen in Table I. Although the majority (34.3\%) had between 1 - 5 years of experience, there was not much difference with other groups. Meanwhile, the non-pharmacists with less than one year, 6 - 10 years, and more than ten years were all $21.9 \%$.

Naturally, all humans will look for complete and qualified health service facilities, including facilities, infrastructures, and human resources, to carry out their health checks. Therefore, community health centres that have better facilities will be visited more by the community (Mustafa \& Shekhar, 2020). Puskesmas are primary health care centres located in sub-districts and villages, so their existence plays an important role in providing the best health services to people in the puskesmas working area (Mustafa \& Shekhar, 2020). Drug preparation is the most important part of the puskesmas facilities considering that drugs are part of the chain between patients and health services, and they can encourage public confidence in the health 
service facility (Quick, 2012). Lack of drugs will cause customer dissatisfaction and increase workload (Heiskanen et al., 2015), which will lead to the administrators implementing strategies that will optimise patient care (Donnelly et al., 2018). Otherwise, the health of the patients will be adversely affected, and conflicts could be caused between professionals (Abdelrahman et al., 2016).

The reason why respondents still receive drugs that are approaching their expiration date is that at the local Health Office, there are no other drugs that aren't near their expiration date. Thus, patients accept the drug very compulsively because there are no other alternatives. This is a necessity considering that health workers who have the competence and authority related to the pharmaceutical practice are pharmacists. Their education has been almost completely devoted to understanding drugs in all of their aspects. As a result of their knowledge, skills, accessibility and ability to carry out good drug management, pharmacists are placed to ensure the availability of qualified, safe and efficacious drugs in all health facilities; this is in addition to the aspect of service as the pharmacists' expertise and authority (Canadian Pharmacists Association, 2004). Good drug management, such as careful selection of essential drugs, good quality assurance, sustainable procurement, supply management and rational drug use, all serve to optimise the use of limited government funds and optimise the provision of basic services for all people (Hogerzeil, 2006). Therefore, it is important to have a drug administrator at a health centre who has the competence and authority in accordance with the applicable law and regulation and who is a pharmacist. Pharmacists are important for public health as a whole and must be involved in the development and implementation of strategies to protect drug supply chains (Costantino, 2020). Pharmacists who are involved in purchasing drugs, especially at the puskesmas, are able to directly procure screen suppliers and ask about the availability of drugs at these suppliers. Companies with drug stock capabilities will be able to provide an uninterrupted supply of drugs even if production facilities experience problems (Costantino, 2020).

The availability of drugs in health facilities is something that absolutely should be controlled because drugs can save lives and improve public health. Most of the main causes of discomfort, disability and premature death can be prevented or treated with drugs, especially using vital and essential drugs (Quick, 2012). Thus, the shortage of drugs in health care facilities will affect the safety of patients who are undergoing outpatient and inpatient care. Drugs that are not available in health care facilities can cause drug-related problems, including patients not getting drugs and patients stopping taking drugs prematurely (Tuti, Athiyah \& Utami, 2018).

The drug availability in relation to drug needs depends on the accuracy of the drugs needs plan (RKO) carried out by the implementer, especially considering their quantification (Athijah, Rahem \& Setiawan, 2018). Quantification is the first step in the procurement process. Quantification is a process used to determine how many pharmaceutical products are required for procurement purposes. In addition, it also estimates how much money is needed to buy the item. Patient needs are estimated for specific conditions in the health facility, so the analysis should include contextual factors, such as available funds, human resource capacity, storage space capacity, and capacity to provide services. The purpose of quantification is to maintain the most cost-effective balance between service levels and costs (Quick, 2012).

In table II of the results of this study, the considerations applied by pharmacists as a determinant of quantification were: the combination of consumption and morbidity patterns in addition to the consideration of the VEN priority scale and $A B C$ analysis. Meanwhile, the administrators only created the consumption patterns. If the quantification method carried out by the drug administrator was related to the suitability of RKO with drug availability, then it showed better results in the quantification of the combination of various methods when compared to only one method of consumption. Namely, $90 \%$ for the combination quantification method and $68 \%$ for the consumption method alone, as presented in Table II. Based on the statistical analysis shown in table III, the value of $p=$ 0.0001 was obtained, meaning that there was a significant difference between the suitability of RKO and those required by pharmacists and nonpharmacists. This was in accordance with the research carried out by Rahem (2017), which showed that quantification using only one method of consumption has the potential for incompatibility between RKO and drug availability because disease patterns in an area can change depending on seasons and the replacement of medical personnel who practice in these health service facilities (Rahem, 2017).

The drug procurement process does not end after the drugs are ordered and received. Managing drug supplies at the puskesmas can be seen as a component of the procurement process that requires a management fund so that the quality of drugs stored at the puskesmas can be maintained. The objective of inventory management is to maintain the minimum amount of inventory required for services in order to control drug costs. Excess inventory can substantially increase management costs and potentially increase 
the number of damaged and expired drugs, as well as drugs with out of control stock. A sufficient amount of drugs must be maintained so that there can be a continuity of drug service according to patient needs. A systematic process should be developed and maintained to check the expiration dates of drugs and remove expired drugs from the inventory. The type of expired drugs should be evaluated, as they may yield useful information that can be used as a basis for reducing availability, especially for drugs that are found to be consistently expired (Peterson, 2005).

The results of the study, as seen in Table II, showed that the percentage of excess drugs stocked in health centres managed by non-pharmacists was greater when compared to drug centres managed by pharmacists. Non-pharmacists stocked between 10 and $40 \%$ of excess drugs, and pharmacists stocked between 10 and $20 \%$ of excess drugs. In line with that, the number of expired drugs and damaged drugs was also larger when managed by non-pharmacists, ranging from $5-18 \%$ for expired drugs and $2-16 \%$ for damaged drugs. Meanwhile, for drugs managed by pharmacists, there was a maximum of $2 \%$ of damaged and expired drugs. A large number of excess drugs stocked resulted in a large number of dead drug stocks. In this study, the stock of dead drugs for health centres managed by pharmacists was $2-7 \%$, while in the health centres managed by non-pharmacists, the stock of dead drugs ranged from $2-15 \%$.

From all aspects studied, it has been shown that drug management at the puskesmas carried out by pharmacists is better than when managed by nonpharmacists. For this reason, it is hoped that the government will place pharmacists at the puskesmas considering that they have the ability to maintain an adequate supply of drugs in all conditions, including during a health crisis. Pharmacists have the capability to strategically address the risk of drug shortage and monitor supply from distributors, including directly dealing with drug manufacturers (Li et al., 2020). Pharmacists can carry out assessments by talking to patients, preparing treatment plans tailored to the patients' needs, as well as explaining and educating about diseases, medications and lifestyle modifications. The pharmacists also prescribe therapy management plans for the patient. The pharmacists use their expertise to try and explain the reasons for therapy failure if that occurs. Pharmacists can communicate with doctors about medication to discuss problems with a patients' treatment (Chandrasekhar et al., 2019). Pharmacists monitor adverse drug reactions (ADR), evaluate and analyse patients' symptoms and provide ADR information to physicians (Ying, Qian \& Kun, 2020). Therefore, treatment becomes more rational, and the success of therapy can be increased.
With the presence of pharmacists in health care facilities, including hospitals, there will be a significant decrease in the number of drugs used, resulting in a decrease in the cost of drug therapy (Aljbouri et al., 2013).

\section{Conclusion}

The role of pharmacists in managing drug inventories is very vital because they can manage them more efficiently and effectively so that the budget can be used very efficient as the planning for drug needs is more accurate, and loss due to damaged and expired drugs can be controlled. Based on the facts in this study that pharmacists are more competent in managing drugs compared to non-pharmacists, and referring to the prevailing law and regulation in Indonesia that those who have expertise and authority in carrying out pharmaceutical practices are pharmacists, it is recommended that all health centres in Indonesia recruit pharmacists.

\section{Conflict of interest}

The authors state that there were no conflicts of interest in this study, and the article.

\section{Authors' declaration}

The authors hereby state that the data and all contents presented in this article were original research results produced by the authors. Any liability for claims relating to the content of this article will be borne by the authors.

\section{Acknowledgements}

The authors would like to thank the Dean of the Faculty of Pharmacy, Universitas Airlangga, who funded this research with the 2019 Research Grant. Their gratitude also goes to the Head of the National Unity and Political Agency of East Java Province who gave permission for this research and to several Heads of the Health Service in East Java, as well as the Head of the puskesmas which was where the research was carried out thanks to the permission that was granted. 


\section{References}

Abdelrahman, A. A., Saad, A. A., Sabry, N. A., \& Farid, S. F. (2016). Perceptions of Egyptian physicians about drug shortage during political disturbances: Survey in Greater Cairo. Bulletin of Faculty of Pharmacy, Cairo University, 54(2), 191-196. https://doi.org/10.1016/j.bfopcu.2016.05.004

Aljbouri, T. M., Alkhawaldeh, M. S., Abu-Rumman, A. eddeen K., Hasan, T. A., Khattar, H. M., \& Abu-Oliem, A. S. (2013). Impact of clinical pharmacist on cost of drug therapy in the ICU. Saudi Pharmaceutical Journal, 21(4), 371-374. https://doi.org/10.1016/j.jsps.2012.12.004

Athijah, U., Rahem, A., Setiawan, C. D. (2018). An Analysis of Drug Requirement Plan and its Relationship with antihypertension drug Availability at Community Health Centers. Int J Pharma Res Health Sci, 6(4), S2739-S2743.

Athiyah, U., Rahem, A. (2017). Analysis of Drug Management Influence With the Success of Theraphy on Members of Pandangdia Patients With Diabetes Mellitus, 7, 182-190.

Canadian Pharmacists Association. (2004). A Review of Pharmacy Services in Canada and the Health and Economic Evidence. https://www.pharmacists.ca/cpha-ca/assets/File/cpha-on-theissues/Pharmacy\%20Services\%20Report\%201.pdf

Chandrasekhar, D., Joseph, E., Ghaffoor, F. A., \& Thomas, H. M. (2019). Role of pharmacist led home medication review in community setting and the preparation of medication list. Clinical Epidemiology and Global Health, 7(1), 66-70. https://doi.org/10.1016/j.cegh.2018.01.002

Costantino, R. C. (2020). The U.S. medicine chest: Understanding the U.S. pharmaceutical supply chain and the role of the pharmacist. Journal of the American Pharmacists Association. 1- 6. https://doi.org/10.1016/j.japh.2020.07.018

Donnelly, K. A., Zocchi, M. S., Katy, T. A., Fox, E. R., van den Anker, J. N., \& Mazer-Amirshahi, M. E. (2018). Prescription Drug Shortages: Implications for Ambulatory Pediatrics. Journal of Pediatrics, 199, 6570. https://doi.org/10.1016/j.jpeds.2018.04.008

Franco, C., \& Alfonso-Lizarazo, E. (2020). Optimization under uncertainty of the pharmaceutical supply chain in hospitals. Computers and Chemical Engineering, 135, 106689. 1 - 13 https://doi.org/10.1016/j.compchemeng.2019.106689

Heiskanen, K., Ahonen, R., Karttunen, P., Kanerva, R., \& Timonen, J. (2015). Medicine shortages - A study of community pharmacies in Finland. Health Policy, 119(2), 232-238. https://doi.org/10.1016/j.healthpol.2014.11.001

Hogerzeil, H. V. (2006). Essential medicines and human rights: what can they learn from each other?. Bulletin of the World Health Organization, 84(5), 371-375.

Istiqomah, F. N., Satibi. (2012). Evaluation of Pharmaceutical Care Standard Implementation by Pharmacist, Journal of Management and Pharmacy Practice. 2(3) $127-132$

Li, M., Razaki, H., Mui, V., Rao, P., \& Brocavich, S. (2020). The pivotal role of pharmacists during the 2019 coronavirus pandemic. Journal of the American Pharmacists Association, 60(6), e73-e75. https://doi.org/10.1016/j.japh.2020.05.017

Merkuryeva, G., Valberga, A., \& Smirnov, A. (2019). Demand forecasting in pharmaceutical supply chains: A case study. Procedia Computer Science, 149, 3-10. https://doi.org/10.1016/j.procs.2019.01.100

Mustafa, A., \& Shekhar, C. (2020). Is quality and availability of facilities at Primary Health Centers (PHCs) associated with healthcare-seeking from PHCs in rural India: An exploratory crosssectional analysis. Clinical Epidemiology and Global Health, (October), 1-6. https://doi.org/10.1016/j.cegh.2020.10.001

Ningsih, A., Fudholi, A., \& Sumarni, S. (2015). Relationship of Application Catalogue Electronic Toward Efficiency Procurement and Availability of Drug. Journal of Management and Pharmacy Practice, 5(4), 233-240.

Nunes, F. G., Anderson, J. E., \& Martins, L. M. (2015). Patient reactions to community pharmacies' roles: Evidence from the Portuguese market. Health Expectations, 18(6), 2853-2864. https://doi.org/10.1111/hex.12269

Sanjaya, G. Y., Hidayat, A. W. (2013). Monitoring of Drug and Medical Logistic in Indonesia : Challenge and Development, Journal of Management and Pharmacy Practice, 159-168.

Peterson, A. M. (2005). Managing Pharmacy Practice, Principles, Strategies, and Systems. CRC PRESS Boca Raton London New York Washington, D.C.

Quick, J. D. (2012). MDS-3: Managing Access to Medicines and Health Technologies. Arlington, VA: Management Sciences for Health.

Rahem, A. (2017). Profile of Management and Availability of Oral Anti Diabetes Drugs at Primary Healthcare Centers. Jurnal Farmasi Dan IImu Kefarmasian Indonesia, 4(2), 75-80.

Saha, E., \& Ray, P. K. (2019). Modelling and analysis of inventory management systems in healthcare: A review and reflections. Computers and Industrial Engineering, 137(September), 106051. 1-6. https://doi.org/10.1016/j.cie.2019.106051

Satibi, S., Daulay, E. H., Oviani, G. A., Erlianti, K., Fudholi, A., \& Puspandari, D. A. (2018). Performance Analysis of Pharmacist and Influencing Factors in the Era of National Healt Insurance at Puskesmas. Journal of Management and Pharmacy Practice, 8(1), 32 - 38. https://doi.org/10.22146/jmpf.34441

National Statistic Bureau. (2016). Jumlah Puskesmas menurut Kabupaten/Kota di Provinsi Jawa Timur (The number of Puskesmas in East Java). Surabaya. Retrieved from https://jatim.bps.go.id/statictable/2018/02/12/938/banyak nya-puskesmas-menurut-kabupaten-kota-di-provinsi-jawatimur-2001-2016.html

Tuti, S. D., Athiyah, U., \& Utami, W. (2018). Factors Aff ecting The Drugs Availability on Program Rujuk Balik ( PRB ) at. Jurnal Ilmu Kefarmasian Indonesia, 16(1), 30-35.

Uthayakumar, R., \& Priyan, S. (2013). Pharmaceutical supply chain and inventory management strategies: Optimization for a pharmaceutical company and a hospital. Operations Research for Health Care, 2(3), 52-64. https://doi.org/10.1016/j.orhc.2013.08.001

van de Pol, J. M., Koster, E. S., Hövels, A. M., \& Bouvy, M. L. (2019). How community pharmacists prioritize cognitive pharmaceutical services. Research in Social and Administrative Pharmacy, 15(9), 1088-1094. https://doi.org/10.1016/j.sapharm.2018.09.012

van de Pol, J. M., van Dijk, L., Koster, E. S., de Jong, J., \& Bouvy, M. L. (2020). How does the general public balance convenience and cognitive pharmaceutical services in community pharmacy practice. Research in Social and Administrative Pharmacy, (November 2019), 1-6. https://doi.org/10.1016/j.sapharm.2020.05.014

Ying, W., Qian, Y., \& Kun, Z. (2020). Drugs supply and pharmaceutical care management practices at a designated hospital during the COVID19 epidemic. Research in Social and Administrative Pharmacy, (April), 1-6. https://doi.org/10.1016/j.sapharm.2020.04.001 